ARTICLE

\title{
Evaluation of health intervention: a case of preschool children in Egypt
}

\author{
Rania Megally ${ }^{1 凶} \&$ Hebatallah Ghoneim (iD ${ }^{2 凶}$
}

\begin{abstract}
Good health and well-being" is the third of the Sustainable Development Goals, but it cannot be achieved without achieving goal two, "No Hunger." Nutrition status is the foundation for healthy individuals, especially children. Developing countries have to set policies to solve malnutrition in order to ensure better health and well-being. This led the researchers to evaluate the impact of nutrition intervention on health outcomes in preschool children in Egypt, a lower middle-income country with high levels of poverty, food insecurity, and anemia. The prevalence of anemia represents a major public health problem in the country; reaching $39.6 \%$. The analysis is based on a control randomized design to measure the impact of nutrition intervention. The sample of this study consisted of 405 children across seven kindergarten classes in Egypt. The results of the study did not show a significant improvement in rates of anemia, stunting, and obesity, likely due to the short treatment period. The results of this research are expected to provide important insights for policy implications under the assumption that this may be a vital step in the process of improving children's health and school performance. Moreover, the results were inspiring enough that this randomized control trial research design has been applied to another study, using a longer-period nutrition program with a larger sample size that will measure the impact of nutrition interventions on children's health and cognition as reflected in the children's school performance and later in their productivity in the labor market.
\end{abstract}

\footnotetext{
${ }^{1}$ British University in Egypt, Giza 12556, Egypt. ${ }^{2}$ German University in Cairo, New Cairo City 11835, Egypt. ${ }^{凶}$ email: rania.megally@bue.edu.eg; hebatallah. ghoneim@guc.edu.eg
} 


\section{Introduction}

oes poor health damage the productivity of people in developing countries? How can health affect the outcomes of the labor market in terms of participation in the labor force and subsequent wages? Have chronic diseases, often neglected by studies, been taken into consideration by policymakers in the developing world? Are improvements in the health levels of the poor enough for them to function, be productive, raise earnings, and develop economies? These questions are raised in a vast array of economic literature stressing the importance of a healthy populace as a precondition for successful development.

Health in childhood has a lifelong impact on schooling, earning potential and future health (Lawlor et al., 2006; Black et al., 2007; Currie and Moretti, 2007). It has also been demonstrated that poor health in childhood can have both direct and indirect effects on schooling, represented in missed school days and cognitive development, respectively. Thus, investment in human capital is crucial for the speedy expansion of economic development and growth in developing countries.

Egypt is one of the lower middle-income countries that have high levels of poverty, food insecurity, and anemia; the last of these is considered a major public health problem in the country. Focusing on the prevalence of anemia among preschoolers, rates have reached 39.6\% (Tawfik et al., 2015). Upper Egypt represents the regional area that is most highly affected by such problems; however, it has expressed less concern (Khatab, 2010; Ecker et al., 2016). Recently, the Egyptian government began a campaign to screen for and treat hepatitis $C$; the program was later extended to screen for other NCDs. Anemia is included among these because it represents a significant burden on Egypt's economy (UNICEF, 2018).

These concerns motivated a study into the impact of proper nutrition on the school performance of children in Egypt. The current study is considered a response to the call from Egypt's scientific community to generate rigorous evidence on effective interventions that target the improvement of nutrition in Egypt. Furthermore, it also attempts to fill the gap that exists in the literature regarding the effectiveness of nutrition intervention in improving health. To these ends, this paper will evaluate the impact of nutrition intervention on the rates of anemia and anthropometric measurements of preschool children ranging from 2 to 6 years of age. The paper will also provide insight on a policy recommendation that can be used to enhance children's health through a nutrition system provided at schools. Egypt is the focus of this paper because of its high rate of problems related to under nutrition among the children (Khatab, 2010) and its geographical location and social and historical links to other countries in the region.

The research held a quasi-experiment that targeted estimating the impact of giving an iron-fortified sirup to children and estimating the impact of such intervention. The study covered seven kindergartens in Egypt, representing three regions: Cairo, BeniSweif, and Sohag. These regions are similar in terms of poverty rates, parent education level and income, and the type of teaching and curriculum in school. Moreover, due to their geographical locations, these kindergartens are representative of Egyptian society-namely Upper Egypt, whose population is $25.5 \%$ of the total Egyptian population.

This introduction states the motive for conducting such a study and the aim, which was mostly inspired by literature discussing similar randomized control trials. It is followed by a literature review, then an overview of the data and methodology used for this study. Subsequently, the analysis details descriptive statistics of the data and estimated results measuring the impact of the intervention. Finally, concluding remarks summarize the results of the study and its implications.

\section{Literature review}

The current paper is modeled on a study conducted in the South African country of Botswana: after providing a treatment of micronutrient beverages for 8 weeks, there was a significant improvement in weight and the weight-for-age $z$-scores of the treated children relative to the children in the control group. Such a treatment is effective when used on a short-term basis; as it is a sweetened beverage, long-term use is advised against so as to avoid the risk of tooth decay and obesity (Abrams et al., 2003).

Many researchers have studied the impact of fortified supplements on the health outcomes of preschool-age children, including hematologic outcomes and anthropometric measures. Eichler et al. (2012) provides a meta-analysis of these studies, measuring the impact of micronutrient-fortified foods on children's health outcomes. The results showed that 13 studies demonstrated a $0.62 \mathrm{~g} / \mathrm{dl}$ increase in the mean level of hemoglobin among treated children relative to the level of hemoglobin among children in the control groups. In another study conducted on anemic children in Indonesia, children in the treatment group were provided iron supplements containing $30 \mathrm{mg}$ of iron and $20 \mathrm{mg}$ of vitamin C. The results indicated a significant improvement not only in hematological values but also a significant increase in the height-for-age $z$-score, which is reflective of a decrease in the rate of stunting as a result of the iron supplements (Angeles et al., 1993).

Ali et al. (2014) ran a study in Egypt's Dakhlia Governorate to assess the prevalence of malnutrition among children under 5 years of age, using a sample population of 358 children. A similar study was conducted on a sample of 397 children ranging in age from 6 months to 15 years of age, thus representing the children in Al-Basra, a district in Alexandria; all were subjected to anthropometric measurements and clinical and laboratory examinations that included complete blood analysis and hemoglobin level assessments (Barakat et al., 2013). El-Eskafy's (2008) randomized controlled intervention study took place over an 8week period in El-Menoufia. The aims of the study were to improve the preschool children's nutrition status with fortified snacks, as well as to estimate the impact of the snacks and their extent of acceptability among the children. The study found that the nutritional intervention had a beneficial influence; however, both the small sample size of 43 children and the population being limited to only students of private kindergartens place limits on the generalizability of this study.

Few other studies assess the prevalence of malnutrition and anemia among children of different ages in Egypt. Two of the major limitations of the above studies are the small sample sizes and the lack of demographic diversity, which undermine the generalizability of the results from an economic perspective. Such a situation applies to all African countries; few studies evaluate the impact of nutrition intervention on the health of preschool children in African countries, although some researchers do recognize the importance of good nutrition for the overall health and cognitive skills of children. These limitations played a major role in motivating the current research, which seeks to address these issues by studying the following data using the using the methodology described below to estimate the impacts of the implemented intervention to estimate the impacts of the implemented intervention.

\section{Methods}

This section of the paper presents the whole data set collected as the baseline, without any drop-outs due to absence or other reasons. Additionally, this section includes a definition of the indicators and variables concerned in this study. An explanation of the study design follows, showing how the intervention was 
implemented and the data collected. The design also includes the statistical methods used to measure the impact of the nutrition intake on the children's health, including their levels of anemia, stunting, malnutrition, and obesity.

Design and sample. The sample for the study consisted of seven kindergartens from Greater Cairo and Upper Egypt. There were 405 children under 6 years of age: around $62 \%$ (251 children) were between 5 and 6 years, while 38\% (154 children) were 5 years of age or younger. The sample size was decided based on available budget, as well as the acceptance of nurseries for participation. The seven kindergartens were randomly divided into six treatment groups of 340 children and one control group of 65 children. The sample included 221 boys (184 treatment and 37 control) and 184 girls (156 treatment and 28 control).

This study was designed as a randomized control trial. First, baseline data were collected in May 2016, the last month of the spring semester of academic year 2015-2016. After parental consent was obtained, kindergartens were randomly divided into treatment and control groups. The treatment, a fortified juice, was provided to all children in the treatment groups. The cost of the treatment was affordable for poor families in case they want to continue using it for the children in the study and their siblings; neither a placebo nor any other incentive or treatment was given to the children in the control group. This nutrition intake took place 4 days a week over a 4 -week period, and it was directly followed by the end-line data collection in order to assure the availability of the children before they started their summer vacation.

Dosage and period of treatment were decided after discussion with more than one pediatrician and thorough review of experiments discussed in previous literature, such as SoteloCruz et al. (2002) and Schultink et al. (1995). Nevertheless, the research period was limited by the budgetary constraints and the availability of the children at the kindergartens.

Dependent and independent variables. Descriptions of the dependent and independent variables used in the data analysis can be found in Table 1. The method of collecting information for these variables is explained extensively in the following subsection. Also, one more dummy variable is added that differentiate children from treatment group vs those from control group.

Tools. Hemoglobin, height, weight, and hematocrit levels (HCTs) were measured for a baseline before and after treatment inside the nurseries. These variables to evaluate health were chosen based on previous literature (Jamison, 1986; Moock and Leslie, 1986; Alderman et al., 2006; Khanam et al., 2011). Demographic

\section{Table 1 Dependent and independent variables.}

\begin{tabular}{|c|c|c|c|c|}
\hline Dependent & Type & Measuring unit & Min. & Max. \\
\hline \multicolumn{5}{|l|}{ Anemia } \\
\hline Hemoglobin & Numeric & $g / l$ & 4.6 & 16.4 \\
\hline Hematocrit & Numeric & $\%$ & 12 & 48 \\
\hline \multicolumn{5}{|c|}{ Anthropometric measurements } \\
\hline height-for-age category & Category & No unit & -2 & 2 \\
\hline weight-for-age category & Category & No unit & -2 & 2 \\
\hline weight-for-height z-score & Ratio & No unit & -4.96 & 3.07 \\
\hline \multicolumn{5}{|l|}{ Independent } \\
\hline Age & Numeric & years & 2.28 & 6.96 \\
\hline Height & Numeric & $\mathrm{cm}$ & 76.5 & 120 \\
\hline Weight & Numeric & $\mathrm{kg}$ & 8 & 25 \\
\hline
\end{tabular}

information was also collected regarding the children's age, gender, location, and health history.

In order to assure the validity and reliability of the tools used to measure levels of anemia, the first step toward evaluating health outcomes, pediatricians running similar projects on children living in Egypt were consulted. They recommended using the hemoglobin meters used in similar research by the faculty of medicine at Ain Shams University ${ }^{1}$ because they give immediate results. These devices are certified worldwide and have the mandatory conformity marking " $c \in$ ". ${ }^{2}$ Such devices have been used to avoid bias that may arise due to differences between clinics in different regions; thus, they assure consistency. Such devices are used by drawing a small amount of blood, which is then placed upon a testing sheet and inserted into the device. ${ }^{3}$ The device then displays readings for hemoglobin and HCTs.

The level of anemia was observed by assessing the hemoglobin concentration and HCTs of the children. The anemia cut-offs are defined as follows for children between 2 and 5 years of age: 110 or higher hemoglobin in grams per liter for non-anemia; 110-99 g/l for mild anemia; and 99-70 g/l for moderate anemia and severe anemia. For children 5 years of age or older, the cutoffs are as follows: $115 \mathrm{~g} / \mathrm{l}$ or higher for non-anemia; $114-110 \mathrm{~g} / \mathrm{l}$ for mild anemia; and $109-80 \mathrm{~g} / \mathrm{l}$ for moderate anemia. Given that anemia has consequences even if it is not clinically noticeable, mildly anemic children must not be ignored, as iron deficiency is expected to increase from the time of its detection (WHO, 2011).

Along with the measurement of hemoglobin, basic growth assessments must also be taken into account, as represented in the measurement of a child's weight and height and the comparison of such measurements to growth standards. A profile including the age, weight, and height for each child was recorded, after which their body mass index (BMI) ${ }^{4}$ was determined. Therefore, the metrics of height and weight by age were used. At the conclusion of the measurement of health outcomes, the children were given a fruity sweet (or a bonbon filled with fruit sirup) as a reward for their cooperation.

These anthropometric variables of weight and height were used to calculate $z$-scores for stunting, wasting/obesity, and malnutrition by measuring the ratios of height-for-age, weight-for-height, and weight-for-age, respectively. This was in addition to measuring BMI (Barakat et al., 2013; Khatab, 2010). The $z$-scores were calculated as follows:

$$
z_{i}=\frac{\mathrm{AI}_{i}-\mathrm{MAI}}{\sigma}
$$

where AI represents the anthropometric indicator of the individual, MAI represents the median for a reference population, and $\sigma$ represents the standard deviation for the reference population. As they express the number of standard deviations (SD) below or above the reference mean of corresponding children who are of the same sex and age, lower $z$-scores indicate greater levels of malnutrition (De Onis et al., 1997). Accordingly, children who have height-for-age $z$-scores below -2 SD below the median of the reference population are considered stunted, i.e. short for their age. Children with weight-for-height $z$-scores below -2 SD from the median of the reference population are considered wasted, i.e. underweight relative to their height. Children with weight-for-age $z$-scores below $-2 \mathrm{SD}$ from the median of the reference population are considered underweight; they are either stunted or wasted, if not both (Alderman et al., 2006; Khatab, 2010).

Levels of stunting are categorized based on the $z$-value of height-for-age: a child is categorized as severely stunted if the height-for-age $z$-value is less than -3 , but only moderately stunted if the $z$-value falls between -3 and -2 . If the $z$-score falls between -2 and 3 , then the child is categorized as being of 
normal-to-tall stature relative for his age, and if the $z$-value is $>3$, the child is classified as very tall (De Onis et al., 1997).

A child is considered severely malnourished if the weight-forage $z$-value is less than -3 , but categorized as moderately malnourished if the $z$-value falls between -3 and -2 . If the $z$ value is $>-2$ but $<2$, then a child is considered to be of normal weight relative to their age. A child is considered overweight if the $z$-value falls between 2 and 3, and obese if more than 3 (De Onis et al., 1997).

In addition, obesity level was measured using the weight-forheight $z$-value. A child is considered severely wasted when the weight-for-height $z$-value is $<-3$ and wasted when the $z$-value falls between -3 and -2 . If the $z$-value is $>-2$ and $<2$, the child is considered to be of normal weight relative to his height, but overweight if the $z$-value falls between 2 and 3 . If the $z$-value is more than 3 , the child is considered obese relative to their height (De Onis et al., 1997).

The baseline and the end-line of this study were both collected by measuring the level of anemia via the child's concentration of hemoglobin, measured using blood tests, and basic growth assessments, represented by the measurement of a child's weight and height in comparison to growth standards. The data provided information about the height, weight, and BMI of the children prior to treatment. After measuring the health status of the children in the baseline data collection, the treatment commenced. Following the treatment period, the blood tests were conducted once more to assess the validity of the treatment.

\section{Data analysis}

Data were analyzed using STATA packages to formulate a descriptive analysis and regression analysis.The impact of the nutrition intervention on the level of anemia among the children is estimated using linear regression and logit models with two definitions of anemia. In the first model, the access to treatment is regressed on levels of hemoglobin after the treatment in a linear regression model, and anemia is defined as the level of hemoglobin. The assumption is that the level of anemia among the children in both treatment and control groups is almost the same in the absence of treatment. In the second model, access to treatment is regressed on the category of anemia on the basis of the hematocrit.

The intervention's impact on stunting in children was estimated using a multinomial logistic regression model. Here the level of stunting is identified as the category of height-for-age after the treatment, and access to the treatment is regressed on it. A similar model was used to measure the impact of the intervention on the level of malnutrition, which is identified as the category of weight-for-age after the treatment. Access to treatment is regressed on it to control for the height and weight of the children after the treatment. In addition, the impact of the treatment on rates of obesity is measured by identifying the level of obesity according to the weight-for-height $z$-value after the treatment, where access to treatment is regressed to control for the weight of the children after the treatment.

Descriptive statistics at baseline. This section will illustrate some pre-treatment descriptive statistics as a baseline for the following variables: the level of hemoglobin; height; weight; and the HCT.

As shown in Table 2, only $13 \%$ of the children demonstrated no anemia, thus illustrating the high percentage of children who are anemic. The absence of anemia is assessed based on the following: normal levels are classified as hemoglobin $>11$ at the age of 5 and $>11.5$ at the age of 5 or above. Moderate anemia is classified as hemoglobin being $<11$ if the children's age is $<5$ and $<11.5$ if they are 5 years of age or above. Within the treatment

\section{Table 2 Level of anemia before treatment.}

\begin{tabular}{lllll|} 
Treatment status & \multicolumn{4}{l}{ Anemia category before treatment } \\
\cline { 2 - 5 } & $\begin{array}{l}\text { No } \\
\text { anemia }\end{array}$ & $\begin{array}{l}\text { Moderate } \\
\text { anemia }\end{array}$ & $\begin{array}{l}\text { Severe } \\
\text { anemia }\end{array}$ & Total \\
\hline Control & 9 & 55 & 1 & 65 \\
Treatment & 42 & 266 & 26 & 334 \\
Total & 51 & 321 & 27 & 339 \\
\hline
\end{tabular}

group, 266 children showed moderate levels of anemia (representing $79.64 \%$ of those treated); there were 55 children within the control group who demonstrated the presence of moderate anemia (representing $84.62 \%$ of that group). Severe anemia is defined by hemoglobin levels of $<7$ for children younger than 5 and $<8$ for those 5 and older; relative to the moderately anemic children, fewer children in both groups had severe anemia. Those children who had severe anemia represented $7.78 \%$ of the treatment group (26 children) and only $1.54 \%$ of the control group (one child). Among the 405 children, there were six children who were too frightened to participate in the blood test; as such, it was not possible to establish whether or not they had anemia.

It was also important to measure the levels of stunting and malnutrition using the height-for-age $z$-value and weight-for-age $z$-value. ${ }^{5}$ Among all children whose height-for-age $z$-value had been measured, $18.67 \%$ exhibited severe stunting and around $40 \%$ exhibited moderate stunting, while around $41 \%$ were normal and $<1 \%$ were very tall (see Table 3 ).

A plurality of children in the treatment group (115 children, or $42.28 \%$ ) exhibited moderate stunting according to the pretreatment. The same level of stunting was exhibited by only $30 \%$ of children in the control group. The majority of children in the control group were classified as normal, roughly $65 \%$; by contrast, only about $36 \%$ of children in the treated group were classified as normal. Finally, severe stunting was observed among $21.69 \%$ of those in the treatment group and only $5 \%$ of those within the control group (see Table 4).

For this paper, levels of malnutrition were measured using the weight-for-age $z$-value. Among all children whose weight-for-age $z$-values were measured before the treatment, the majority were classified as normal (around $89 \%$ of all children), whereas only 8.5\% exhibited moderate malnourishment. The lowest percentages were for the categories of severe malnourishment, around $2 \%$, and overweight, $<1 \%$, as shown in Table 5 .

When comparing the levels of malnutrition between the treatment and control groups, the data showed that none of the children in the control group were severely malnourished or overweight; in addition, there were few children in the treatment group who exhibited severe malnutrition $(2.57 \%)$ and who were classified as overweight $(<1 \%)$. The majority of the treated children were normal in terms of nutrition, comprising around $90 \%$ of the group; as for the control group, around $87 \%$ were considered normal. The moderately and severe children consisted $7.35 \%$ of the treatment group and $13.33 \%$ of the control group (based on data in Table 6).

In addition, the level of obesity was measured using the weightfor-height $z$-value. The majority of the children were normal (around 87\%), while only 3.6\% were wasted and $7.14 \%$ were overweight. The lowest percentage was found among those who exhibited obesity (around 1.5\%), as shown in Table 7.

Table 8 shows an overview of obesity among the two groups prior to treatment, illustrating the distribution between treatment and control. 
Table 3 Stunting level before treatment.

\begin{tabular}{llll}
$\begin{array}{l}\text { Stunting category before } \\
\text { treatment }\end{array}$ & Frequency & Percent & Cumulative \\
\hline Severe stunting & 62 & 18.67 & 18.67 \\
Moderate stunting & 133 & 40.06 & 58.73 \\
Normal & 136 & 40.96 & 99.70 \\
Very Tall & 1 & 0.30 & 100 \\
Total & 332 & 100 & \\
\hline
\end{tabular}

Table 4 Stunting level before treatment categorized by treatment vs. control.

Treatment status Stunting level

\begin{tabular}{|llllll} 
& $\begin{array}{lllll}\text { Severe } \\
\text { stunting }\end{array}$ & $\begin{array}{l}\text { Moderate } \\
\text { stunting }\end{array}$ & Normal & Very tall & Total \\
\hline Control & 3 & 18 & 39 & 0 & 60 \\
Treatment & 59 & 115 & 97 & 1 & 272 \\
Total & 62 & 133 & 136 & 1 & 332 \\
\hline
\end{tabular}

Table 5 Malnutrition level before treatment.

Malnutrition category before pilot Frequency Percent Cumulative treatment

\begin{tabular}{llll}
\hline Severely malnourished & 7 & 2.11 & 2.11
\end{tabular}

$\begin{array}{llll}\text { Moderately malnourished } & 28 & 8.43 & 10.54\end{array}$

$\begin{array}{llll}\text { Normal } & 295 & 88.86 & 99.40\end{array}$

$\begin{array}{llll}\text { Overweight } & 2 & 0.6 & 100\end{array}$

$\begin{array}{lll}\text { Total } & 332 & 100\end{array}$

Table 6 Malnutrition level before treatment, categorized by treatment vs. control.

Treatment Malnutrition category before pilot treatment

status

\begin{tabular}{llllll|}
\cline { 2 - 6 } & $\begin{array}{l}\text { Severe } \\
\text { malnourished }\end{array}$ & $\begin{array}{l}\text { Moderately } \\
\text { malnourished }\end{array}$ & Normal & Overweight & Total \\
\hline Control & 0 & 8 & 52 & 0 & 60 \\
Treatment & 7 & 20 & 243 & 2 & 272 \\
Total & 7 & 28 & 295 & 2 & 332 \\
\hline
\end{tabular}

Table 7 Obesity level before treatment.

Obesity category before pilot Frequency Percent Cumulative treatment

\begin{tabular}{llll}
\hline Wasted & 9 & 3.57 & 3.57 \\
Normal & 221 & 87.7 & 91.27 \\
Overweight & 18 & 7.14 & 98.41 \\
Obese & 4 & 1.59 & 100 \\
Total & 252 & 100 & \\
\hline
\end{tabular}

Table 8 Obesity level before treatment, categorized by treatment vs. control.

Treatment status Obesity category before pilot treatment

\begin{tabular}{llllll|} 
& Wasted & Normal & Overweight & Obese & Total \\
\hline Control & 0 & 29 & 1 & 1 & 31 \\
Treatment & 9 & 192 & 17 & 3 & 221 \\
Total & 9 & 221 & 18 & 4 & 252 \\
\hline
\end{tabular}

Table 9 Estimating randomness of selection.

\begin{tabular}{|c|c|c|c|c|c|c|}
\hline \multirow[t]{2}{*}{ Group } & \multicolumn{2}{|c|}{ Gender } & \multicolumn{2}{|c|}{$\begin{array}{l}\text { Weight-for-age } \\
\text { z-score }\end{array}$} & \multicolumn{2}{|c|}{$\begin{array}{l}\text { Weight-for-height } \\
\text { z-score }\end{array}$} \\
\hline & Obs & Mean & Obs & Mean & Obs & Mean \\
\hline Control & 59 & 0.41 & 59 & -0.94 & 28 & -0.03 \\
\hline Treatment & 276 & 0.46 & 272 & -0.85 & 183 & 0.22 \\
\hline Combined & 335 & 0.45 & 331 & -0.87 & 211 & 0.18 \\
\hline Difference & & -0.05 & & -0.09 & & -0.25 \\
\hline $\operatorname{Pr}(|T|>|t|)$ & & 0.49 & & 0.51 & & 0.40 \\
\hline
\end{tabular}

Validation of research design. Validation of the current research design was conducted by testing the equality between the means of certain variables across the treatment and control groups prior to implementation of the treatment. This equality between the means estimates the probability that the difference between the means is due to randomness rather than any systematic difference. Such an equality test was conducted using a sample of variables, such as age, weight-for-age $z$-score, and weight-forheight $z$-score.

Testing for gender indicates a $49 \%$ probability that the difference between the means of the female children within the treatment and control groups is due to the random selection of the groups. Hence, the null hypothesis, which assumes no difference in the means of children's gender between treatment and control groups (as observed in Table 9), will not be rejected.

Similarly, tests of weight-for-age $z$-score and weight-for-height $z$-score showed that there is a $50 \%$ probability and a $40 \%$ probability, respectively; that the differences between the means of the obese children in terms of weight-for-age or weight-forheight $z$-score in treatment and control groups are due to randomness. This implies that the null hypothesis, which assumes no difference in the means of children's malnutrition and obesity levels between treatment and control groups (as observed in Table 9), cannot be rejected.

Ethics. Parents, school principals, and teachers were given a detailed explanation of the study's aims and procedures. Parents had to sign a written consent form (see Supplementary Information). In addition, a training session was conducted for the teachers involved in the treatment, and teachers were monitored for their performance during the treatment period and data collection.

\section{Regression results}

Estimating the impact of nutrition intervention on anemia level. To estimate the causal effect of the fortified juice on the rates of anemia in Upper Egypt, the following outcomes equations were modeled:

$$
Y_{i}=\beta_{0}+\beta_{1 i} \text { treat }_{i}+u_{i}
$$

where $Y_{i}$ is a continuous variable representing the level of hemoglobin after the treatment; treat $_{i}$ is a dummy variable, assigned a value of 1 if a given child $i$ received the treatment and 0 if they did not; and $u_{i}$ represents error.

$$
Y_{i}=\beta_{0}+\beta_{1 i} \text { treat }_{i}+u_{i}
$$

where $Y_{i}$ is a continuous variable representing the HCT after the treatment, treat ${ }_{i}$ is a dummy variable that represents whether a given child $i$ did (1) or did not (0) receive the treatment, and $u_{i}$ refers to the error term.

According to the WHO (2011), the most reliable and efficient indicator for measuring the impact of a treatment on the level of anemia is the improvement of the level of hemoglobin and/or 
Table 10 Estimating the effect of the treatment in the pilot study on levels of anemia.

Impact of nutrition intervention on anemia level

\begin{tabular}{lllll}
\hline & (1) Hemoglobin & (2) Hematocrit & (1) (Robust) Hemoglobin & (2) (Robust) Hematocrit \\
\hline Treat & $-1.22^{\star \star \star}(0.2796328)$ & $-3.47^{\star \star \star}(0.863656)$ & $-1.22^{\star \star \star}(0.2494624)$ & $-3.47^{\star \star \star}(0.7506334)$ \\
Observations & 257 & 256 & 257 & 256 \\
$R^{2}$ & 0.07 & 0.04 & 0.07 & 0.04 \\
\hline
\end{tabular}

$\star \star \star$ It is significant with less than $1 \%$ significance level.

hematocrit. This is especially true in the pilot stage, given the short period of treatment.

The linear regression models (1) and (2) demonstrated a significant effect of the treatment on the levels of hemoglobin and hematocrit. The results are presented in Table 10. However, the coefficient of the treatment was negative, indicating that the treatment reduced the hemoglobin and HCT. This may not sound logical; however, the spread of jaundice among the children of one of the kindergartens may explain such overall results. ${ }^{6}$

Estimating the impact of nutrition intervention on stunting level. After measuring the impact of the nutrition intervention on anemia level, the following model is used to estimate the impact of the nutrition intervention on stunting level:

$Y_{i}=\beta_{0}+\beta_{1 i}$ treat $_{i}+\beta_{2 i}$ AHeight $_{i}+\beta_{3 i}$ AWeight $_{i}+\beta_{4 i}$ Age $_{i}+u_{i}$

where $Y_{i}$ is a categorical variable representing height-for-age, after the treatment, ranging from -2 to 2 according to the height-forage $z$-value as previously specified; treat ${ }_{i}$ is a dummy variable, assigned a value of 1 if a given child $i$ received the treatment and 0 if not; AHeight ${ }_{i}$ refers to the height of child $i$ after the treatment period; AWeight ${ }_{i}$ refers to the weight of child $i$ after the treatment period; $\mathrm{Age}_{i}$ refers to the age of each child $i$, and $u_{i}$ refers to the error term. Based on the fact that the dependent variable is a categorical variable (height-for-age categories), the best method to explain the variation would be the multinomial logistic regression, as illustrated by the following outcomes.

The model that best explains the impact of the treatment on the level of stunting is Model (3), which controls for the height and weight after the treatment, as well as age. It shows that treatment has an impact on the stunting level, with a 5\% significance level for the moderately stunted children; however, no significant difference was found for either the severely stunted or the very tall children. The coefficient of the treat variable for the moderately stunted children shows that the relative probability of the child to be moderately stunted rather than being normal is $1.4 \%$ higher for those who received the treatment compared to those who did not (as shown in Table 11). On the other hand, none of the models showed a positive impact of the treatment on the level of malnutrition, given that each model controls for different explanatory variables. Using the robust standard errors shows higher significance for the "very tall" category only, but there was no difference in the significance level among the other categories.

Estimating the impact of nutrition intervention on obesity level. One of the crucial measures that must be considered is the obesity level. Hence, the impact of the nutrition intervention has been also estimated on the obesity level as follows:

$$
Y_{i}=\beta_{0}+\beta_{1 i} \text { treat }_{i}+u_{i}
$$

where $Y_{i}$ is a continuous variable representing the weight-for-height
Table 11 Estimating the effect of the treatment in the pilot study on stunting level.

Impact of nutrition intervention on stunting levelmultinomial logistic regression

\begin{tabular}{|c|c|c|}
\hline & $\begin{array}{l}\text { (3) Height-for-age } \\
\text { category }\end{array}$ & $\begin{array}{l}\text { (3) (Robust) Height-for-age } \\
\text { category }\end{array}$ \\
\hline Severe stunting & 1.48 & 1.48 \\
\hline Treat & 1.05 & (1.049457) \\
\hline $\begin{array}{l}\text { Moderately } \\
\text { stunting }\end{array}$ & $1.44^{\star}$ & $1.44^{\star}$ \\
\hline Treat & 0.76 & $(0.76)$ \\
\hline Normal & Base outcome & Base outcome \\
\hline $\begin{array}{l}\text { Very tall } \\
\text { stature }\end{array}$ & 12.60 & $12.60^{\star \star \star}$ \\
\hline Treat & 1188.34 & $(1.03)$ \\
\hline Observations & 209 & 209 \\
\hline$R^{2}$ & 0.02 & 0.02 \\
\hline
\end{tabular}

Table 12 Estimating the effect of the treatment in the pilot study on obesity level.

Impact of nutrition intervention on obesity level

\begin{tabular}{ll}
\hline & (4) z-score weight-for-height \\
\hline Treat & $0.35(0.2406805)$ \\
Observations & 248 \\
$R^{2}$ & 0.01
\end{tabular}

$z$-value after the treatment according to the weight-for-height $z$-value (as has been specified above), treat ${ }_{i}$ is a dummy variable that represents whether a given child $i$ received (1) or did not receive (0) the treatment, and $u_{i}$ again refers to error (see Table 12).

Child growth is also indicated by the weight-for-height $z$-value, which as previously mentioned measures the level of obesity. The impact of the treatment on the levels of obesity and being overweight was insignificant, as indicated by the results of model (4). This implies that the treatment had no impact on the level of obesity.

\section{Discussion}

Sustainable development begins with the development of people. An economy cannot grow with unhealthy children who suffer from malnutrition and iron deficiency. Governments need to start by improving children's health because their health needs represent a financial burden for poor families.

Given the lack of public nutrition interventions during childhood in Egypt, there has been interference by many international 
organizations, such as the World Food Program, WHO, and UNICEF. In spite of their active role in improving the nutrition of children, their programs have not been sufficiently effective due to the lack of both monitoring and following-up. This has resulted in poor outcomes that have failed to assist the government in planning safety nets for Egypt. For all of these reasons, there was sufficient motivation to conduct a nutrition intervention with preschool children and evaluate its impact using a randomized control trial. Such a study can assist the Egyptian Ministries of Health and Education when considering early childhood nutrition in their developing programs.

The intervention applied in this study, fortified juice intake for one month, did not demonstrate significant impacts on the children's health, including the impacts on levels of anemia, stunting, malnutrition, and obesity. This was expected given the short period of treatment-one month is not enough to create any significant change in the health of children and would be waste of funds. Regardless, the results were supported by a study conducted with anemic children in Zanzibar: iron had no significant impact on the children's wasting, stunting, or rates of malnutrition (Stoltzfus et al., 2004). Another study-testing the impact of multiple types of treatment on the prevalence of iron deficiency anemia-was conducted among Vietnamese children from 6 to 9 years of age. Two treatments were used: fortified biscuits provided daily while a placebo tablet was provided once a week or an iron tablet provided once a week while non-fortified biscuits were provided daily. The results showed a significant increase in the concentration of hemoglobin among both the children who were provided fortified biscuits and the ones who were provided iron tablets. This was relative to the control group (who received only a placebo). However, the height-for-age and weight-for-age $z$-scores showed no significant difference postintervention. This does not deny any reduction in the prevalence of anemia due to the improvement in the level of hemoglobin (Hieu et al., 2012).

Iron supplementation as an approach to prevent iron deficiency is not always effective when implemented in low-income countries. The reason for this is the failure to meet the basic iron requirements of a child's first 6 months of life due to flawed assumptions regarding the presence of iron at birth and in breast milk. This assumption relies on adequate iron during maternity, as well as adequate practices at birth that ease the transfer of iron via placental blood (Chaparro et al., 2006; Hutton and Hassan, 2007) and special breast-feeding. The reason for this is to avoid the loss of pathological iron due to damage to the integrity of the intestinal wall (Dewey and Chaparro, 2007). The interference of other liquids and food during the first 6 months of life plays a significant role in limiting the absorption of the iron available in breast milk (Oski and Landaw, 1980). Hence, interventions may be more effective if they are started earlier, such as during pregnancy and the neonatal period into toddlerhood (Lutter, 2008).

In 2017, UNICEF and Egypt's Ministry of Health and Population cooperated to set a Nutrition Agenda for Action in order to increase nutrition interventions in Egypt. The 2011 nutrition targets from the World Health Assembly (which are supposed to be achieved by 2025) include a $40 \%$ reduction in chronic under nutrition for children 5 years of age and a reduction of wasting in childhood to $<5 \%$. However, Egypt has not been on track to meet these targets (UNICEF, 2017). Consequently, the National Food and Nutrition Policy and Strategy (2007-2017) targeted many policy areas that focus on improving the nutritional situation, food security, and the control and prevention of micronutrient deficiency; however, the absence of clearly allocated funding and proper budgeting for nutrition interventions has increased the challenges faced by proponents of the Nutrition Policy, despite the fact that funding is available for the implementation of smaller programs across the country (IFPRI, 2014). In addition, the health sector proved to be underfunded, with only $6 \%$ of the national budget being allocated to healthcare during the 2014-2015 fiscal years.

\section{Conclusion}

This paper has aimed to highlight the applicability of running randomized control trial research in Egyptian order to better establish a plan for future research. Moreover, this research demonstrated that a 1-month nutrition intervention was not sufficient to improve the health of children, suggesting that longer-period nutrition programs are necessary to treat many health issues faced by poor families in Egypt, especially children. Such research would measure impacts not only on children's health but also on their cognitive development and school performance, and the subsequent results could provide effective support for policy makers when running nutrition interventions. Future research must consider running awareness campaigns and evaluate the impacts of such campaigns, as they may have better effects on children's health and cognition with lower costs.

\section{Data availability}

The datasets analyzed during the current study are not publicly available due to privacy concerns with the funding institution that gave permission for using the data without publishing them but are available from the corresponding authors on reasonable request.

Received: 14 October 2019; Accepted: 18 March 2020; Published online: 06 May 2020

\section{Notes}

1 One of the largest medical faculties in Egypt.

2 This refers to the certification mark, which guarantees high standards for health, environmental protection, and the overall safety of the product (European Commission, 2018).

3 The blood is drawn with a simple needle designed to cause the least amount of pain. $4 \mathrm{BMI}$ is a measure of weight adjusted for height and is calculated by dividing the weight in kilograms by the square of height in meters (Must and Anderson, 2006).

5 A total of 73 children were missing data for at least one of height, weight, and age, leading to missing height-for-age and weight-for-age $z$-values for these children.

6 Jaundice is a liver disease that has a negative effect on the absorption of iron, as well as other minerals and nutrients, as illustrated by low levels of hemoglobin and hematocrit.

\section{References}

Abrams SA, Mushi A, Hilmers DC, Griffin IJ, Davila P, Allen L (2003) A multinutrient-fortified beverage enhances the nutritional status of children in Botswana. J Nutr 133(6):1834-1840

Alderman H, Hoddinott J, Kinsey B (2006) Long term consequences of early childhood malnutrition. Oxf Econ Pap 58(3):450-474

Ali OF, Eladawi N, Abdel-baky A, Abdel-gawad A (2014) Assessment of nutritional status of under 5 years rural children in delta region in Egypt. Aust J Basic Appl Sci 8(15):53-59

Angeles IT, Schultink WJ, Matulessi P, Gross R, Sastroamidjojo S (1993) Decreased rate of stunting among anaemic Indonesian preschool children through iron supplementation. Am J Clin Nutr 58(3):339-342

Barakat AA, Nada KH, Ezzat DA (2013) Prevalence and determining factors of anemia and malnutrition among Egyptian children. Indian J Med Sci 67(7 \& 8):168-177. In:

Black SE, Devereux PJ, Salvanes KG (2007) From the cardle to the labor market? The effect of birth weight on adult outcomes. Q J Econ 122(1):409-439

Chaparro CM, Neufeld LM, Alavez GT, Cedillo REL, Dewey KG (2006) Effect of timing of umbilical cord clamping on iron status in Mexican infants: a randomized controlled trial. Lancet 367(9527):1997-2004

Currie J, Moretti E (2007) Biology as destiny? Short- and long-run determinants of intergenerational transmission of birth weight. J Labor Econ 25(2):231-263 
De Onis M, Blossner M, World Health Organization (1997) WHO global database on child growth and malnutrition. No. WHO/NUT/97.4. World Health Organization, Geneva

Dewey KG, Chaparro CM (2007) Session 4: mineral metabolism and body composition. iron status of breast-fed infants. Proc Nutr Soc 66(3):412-422

Ecker O, Al-Riffai P, Breisinger C, El-Batrawy R (2016). Nutrition and economic development: exploring Egypt's exceptionalism and the role of food subsidies. International Food Policy Research Institute

Eichler K, Wieser S, Rüthemann I, Brügger U (2012) Effects of micronutrient fortified milk and cereal food for infants and children: a systematic review. BMC Public Health 12(1):506

El-Eskafy AMI (2008). Improving the nutritional status of preschool children in ElMenoufia Governorate, Egypt. Inaugural-Dissertation zurErlangung des DoktorgradesimFachberichAgrawissenschaften, Oekotrophologie und Umweltmanagement der Justus-Liebig-Universitaet Giessen

European Commission (2018). CE marking. http://ec.europa.eu/growth/singlemarket/ce-marking/

Hieu NT, Sandalinas F, de Sesmaisons A, Laillou A, Tam NP, Khan NC, Bruyeron O, Wieringa FT, Berger J (2012) Multi-micronutrient-fortified biscuits decreased the prevalence of anemia and improved iron status, whereas weekly iron supplementation only improved iron status in Vietnamese school children. Br J Nutr 108(8):1419-1427

Hutton EK, Hassan ES (2007) Late vs. early clamping of the umbilical cord in fullterm neonates: systematic review and meta-analysis of controlled trails. J Am Med Assoc 297(11):1241-1252

International Food Policy Research Institute (IFPRI) (2014). Egypt global nutrition report. International Food Policy Research Institute (IFPRI), Washington

Jamison DT (1986) Child malnutrition and school performance in China. J Dev Econ 20(2):299-309

Khanam R, Nghiem HS, Rahman MM (2011) The impact of childhood malnutrition on schooling: evidence from Bangladesh. J Biosoc Sci 43(4):437-451

Khatab K (2010) Childhood malnutrition in Egypt using GeoadditiveGuassian and latent variable models. Am Soc Trop Med Hyg 82(4):653-663

Lawlor DA, Clark H, Smith GD, Leon DA (2006) Intrauterine growth and intelligence within sibling pairs: findings from the Aberdeen children of the 1950s cohort. Pediatrics 117(5):e894-e902

Lutter CK (2008) Iron deficiency in young children in low-income countries and new approaches for its prevention. J Nutr 138(12):2523-2528

Moock PR, Leslie J (1986) Childhood malnutrition and schooling in the terai region of Nepal. J Dev Econ 20(1):33-52

Must A, Anderson SE (2006) Body mass index in children and adolescents: considerations for population-based applications. Int J Obes 30:590-594

Oski FA, Landaw SA (1980) Inhibition of iron absorption from human milk by baby food. Am J Dis Child 134(5):459-460

Schultink W, Gross R, Gliwitzki M, Karyadi D, Matulessi P (1995) Effect of daily vs twice weekly iron supplementation in Indonesian preschool children with low iron status. Am J Clin Nutr 61(1):111-115

Sotelo-Cruz N, Gómez-Rivera N, Ferrá-Fragoso S, Pereyda-Galaz DE (2002) Treatment of iron deficiency in preschool children with a weekly dose of ferrous sulfate. Gac Med Mex 138(3):225-230

Stoltzfus RJ, Chway HM, Montresor A, Tielsch JM, Jape JK, Albonico M, Savioli L (2004) Low dose daily iron supplementation improves iron status and appetite but not anemia, whereas quarterly anthelminthic treatment improves growth appetite and anemia in Zanzibari preschool children. J Nutr 134 (2):348-356

Tawfik AA, Hanna ET, Abdel-Maksoud AM (2015) Anemia and iron deficiency anemia in Egypt. J Pharm 5(4):30-34

United Nations International Children's Emergency Fund (UNICEF) (2018). Child malnutrition: unfolding the situation in Egypt. UNICEF Egypt Data Snapshot, (1). https://www.unicef.org/egypt/media/2686/file. Accessed 20 May 2019

United Nations International Children's Emergency Fund (UNICEF) (2017), Nutrition Agenda for Action, a policy paper on scaling-up nutrition interventions in Egypt. https://www.unicef.org/egypt/media/296/file Accessed 20 May 2019

WHO (2011) Hemoglobin concentrations for the diagnosis of anemia and assessment of severity. Vitamin and mineral nutrition information system. World Health Organization, Geneva, 2011 (WHO/NMH/NHD/MNM/ 11.1). http://www.who.int/vmnis/indicators/hemoglobin.pdf. Accessed 20 May 2019

\section{Competing interests}

The authors declare no competing interests.

\section{Additional information}

Supplementary information is available for this paper at https://doi.org/10.1057/s41599020-0450-3.

Correspondence and requests for materials should be addressed to R.M. or H.G.

Reprints and permission information is available at http://www.nature.com/reprints

Publisher's note Springer Nature remains neutral with regard to jurisdictional claims in published maps and institutional affiliations.

(c) (i) Open Access This article is licensed under a Creative Commons BY Attribution 4.0 International License, which permits use, sharing, adaptation, distribution and reproduction in any medium or format, as long as you give appropriate credit to the original author(s) and the source, provide a link to the Creative Commons license, and indicate if changes were made. The images or other third party material in this article are included in the article's Creative Commons license, unless indicated otherwise in a credit line to the material. If material is not included in the article's Creative Commons license and your intended use is not permitted by statutory regulation or exceeds the permitted use, you will need to obtain permission directly from the copyright holder. To view a copy of this license, visit http://creativecommons.org/ licenses/by/4.0/.

(C) The Author(s) 2020 